\title{
The Influence of Realistic Mathematics Education (RME) Approach on Students' Mathematical Representation Ability
}

\author{
A. Fauzan, E. Musdi, R.P. Yani \\ Universitas Negeri Padang, Padang, Indonesia
}

\begin{abstract}
In this research, the researchers compared mathematical representation ability between the students who were taught using Realistic Mathematics Education (RME) and those who were taught using conventional approach, according to their gender and learning styles. This quasi experimental research was carried out at three junior high schools, involving 174 eighth grade students in Bukit Tinggi, Indonesia. Those schools were purposively selected to represent three different categories of schools (high, middle, and low). The data were collected through questionnaires and test. The results showed that the students' mathematical representation ability was higher when they were taught using RME than when the students were taught using conventional approach, irrespective of their gender. Similar findings were found in relation to the students' learning styles, except for the students with auditory learning style from the school in the middle category. In the end, it can be concluded that the RME approach contributed to the improvement of students' mathematical representation ability.
\end{abstract}

Keywords—-tracker software; video-based Analysis

\section{INTRODUCTION}

Mathematical representation is one of important aspects in learning mathematics which plays a role as a device as well as a mathematics instruction. A representation can be used by teachers to instruct, and by students to solve problems and communicate their mathematical ideas to others as well as to translate concrete concepts into an abstract thinking [7,3]. The National Council of Teachers of Mathematics (NCTM) mentioned that mathematics instruction should enable all students to create and use representations to organize, record, and communicate mathematical ideas, and use representations to model and interpret physical, social, and mathematical phenomena [16]. Ball et al. (2008) also suggested representation as a part of the 'specialized content knowledge' of mathematic uniqueness in teaching [1]. In addition, other researchers (see Ozyildirim, Ipek, \& Akkus, 2009; Sedig, K., 2008; Superfine, Canty, \& Marshall, 2009) suggested the importance of representations in learning mathematics [17,20,21].

In Indonesian curriculum, mathematical representation is one of mathematical abilities that need to be developed through mathematic lessons. However, most of mathematics teachers did not seriously concern to develop this ability. The 'chalk and talk' method is prevalent to teach mathematics $[4,5]$. As a result, most students find it difficult to solve mathematical problems which involved mathematical representations.

It was argued in this research that Realistic Mathematics Education (RME) approach would give many opportunities for the students to develop their mathematical representation ability. RME approach is based on Freudenthal's interpretation of mathematics as a human activity [8]. From this perspective, students should learn mathematics by mathematizing subject matter from realistic situations and by mathematizing their own mathematical activity [18]. RME approach is contrary to the conventional approach that has been mostly used by the teachers in Indonesia to teach mathematics.

Conventional approach refers to the way of teaching in which the teacher mostly starts a mathematic lesson by explaining an algorithm or a formula. Then, the teacher gives example(s) to show how the algoritm or formula works, followed by students' activity on solving mathematical problems that are similar to the example(s) given by the teacher [4]. By using conventional approach, the teacher teaches ready-made mathematics which is the mathematics of mathematicians (de Lange, 1987; Gravemeijer, 2010). Meanwhile, RME approach facilitates students to build conceptual understanding using their informal knowledge. If the conventional approach tends to put an algorithm as a strarting point, RME approach puts it as the end of the instruction $[8,4,12]$. To understand an algorithm, the students will work on contextual problems that will gradually give them experiences to find the algorithm by themselves under the guidance of the teacher $[11,13]$. This situation was described by Webb, Koiij, \& Geist (2011) at Figure 1 [23].

In learning mathematics using RME approach, the students will experience how to solve a contextual problem using their informal knowledge. This process is called horizontal mathematization. At the beginning, the students will solve the problems informally using their own ways, their own words, or 


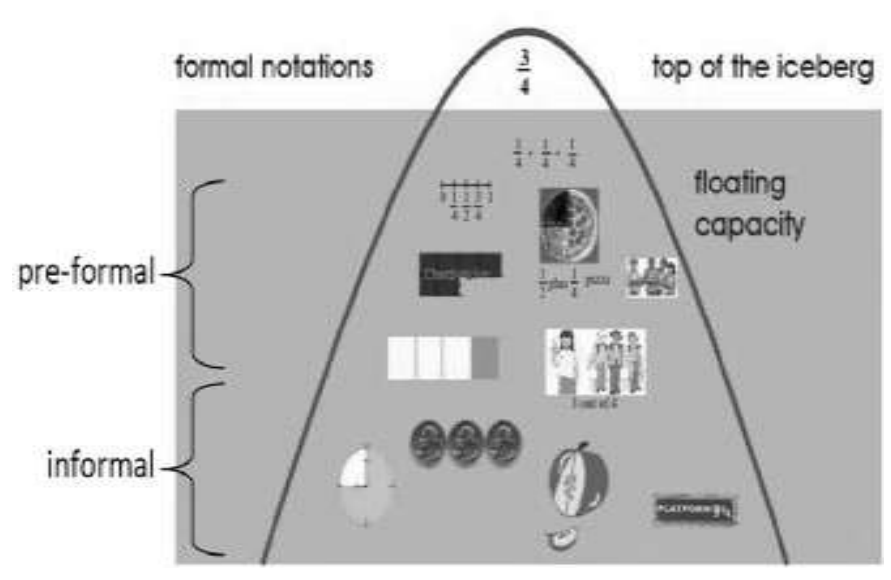

Figure 1. Building conceptual understanding by solving contextual problems using informal knowledge

their own symbols. After experiencing a similar process (trough simplification and formalization), they will use more formal ways or symbols that will lead them to reinvent an algorithm or a formal mathematical concept. This kind of process is called vertical mathematization [22]. In doing horizontal and vertical mathematization, the students will use multiple representations in the form of real-world object, model, pictures, graphs, tables, or symbols.

In comparing the effect of RME and conventional approach on students' mathematical representation ability, we also involved gender and learning styles (auditory, visual, and kinesthetic) of the students as variables. There were some reasons behind this idea. Firstly, most teachers in Indonesia rarely consider gender and learning styles in choosing a particular approach in their teaching of mathematics. Secondly, male or female students or students with a certain learning style might have different preferences in using mathematical representations [2,13]. Thirdly, RME approach accommodates gender and learning styles differences when the students get involved in doing mathematics activities [4]. The differences are also accommodated by the characteristics of RME such as students' free productions, students' contributions, and interactivity (de Lange, 1987; Gravemeijer, 1994). Finally, we want to investigate whether RME approach will be suitable for students with different gender, learning styles, and academic abilities. Related to this purpose, we conducted the research at three schools with different categories (high, middle, and low).

The research questions in this study are stated as follows: 1) Is the representation ability of the students who were taught using RME approach higher than those who were taught using conventional approach? 2) Is the representation ability of male and female students who were taught using RME approach higher than those were taught using conventional approach? 3) Is the representation ability of the students with auditory, visual, and kinesthetic learning styles that were taught using RME approach respectively higher than those were taught using conventional approach?

\section{METHOD}

This study was a quasi-experimental research aimed at comparing the influence of RME approach to the conventional approach on the students' mathematical representation ability. The variables involved in this research were mathematical representation abilities as independent variable, RME approach as dependent variable, and gender as well as learning styles as moderator variables.

The research was carried out at three junior high schools in Bukit Tinggi Indonesia. Each school is identified by the local government with high, middle, and low category respectively, based on the results of the 2016 national examination. From each school, two classes of the $8^{\text {th }}$ grade were chosen randomly as the sample of the research. In total, there were 174 students participated in this research. One class at each school category was assigned as the experimental group and the other class as the control group. The students of the experimental group were taught about Ratio using RME approach while the students in the control group were taught using conventional approach. The instructional design for teaching Ratio using RME approach used in this research was developed in the previous research [6].

The data of the research were collected using questionnaire and test. The questionnaire was used to identify the learning styles of the students, while the test was used to measure the mathematical representation ability of the students. The test was validated by two mathematic experts, then it was tried out to a group of eighth grade students to meet the validity and reliability criteria. The indicators of mathematical representation used in the test were (1) representing data or information using a diagram, a graph, or a table, (2) creating a mathematical equation or a model of a given representation, and (3) interpreting a given mathematical representation. The score of the students' ability in mathematical representations was determined by using scoring rubric created [14]. Furthermore, the data were analyzed using Mann Whitney $U$ and t-test after conducting a series of normality and homogeneity tests.

\section{RESULTS AND DISCUSSION}

Based on data analysis, the students' mathematical representation abilities were classified according to their gender and school categories, as can be seen on Table 1.

TABLE I. THE AVERAGE SCORE OF STUDENTS'MATHEMATICAL REPRESENTATION ABILITY ACCORDING TO THEIR GENDER AND SCHOOL CATEGORIES

\begin{tabular}{|l|l|r|r|r|r|r|c|}
\hline \multirow{3}{*}{ Gender } & \multirow{2}{*}{ Value } & \multicolumn{6}{|c|}{ Schools' Categories } \\
\cline { 3 - 8 } & & \multicolumn{2}{|c|}{ High } & \multicolumn{2}{|c|}{ Middle } & \multicolumn{2}{|c|}{ Low } \\
\cline { 3 - 8 } & & EG & CG & EG & CG & EG & CG \\
\hline Male & $\bar{X}$ & 83.3 & 53.3 & 60 & 58.4 & 78.3 & 56.7 \\
\hline
\end{tabular}




\begin{tabular}{|l|l|l|l|l|l|l|l|}
\hline \multirow{3}{*}{ Gender } & \multirow{2}{*}{ Value } & \multicolumn{6}{|c|}{ Schools' Categories } \\
\cline { 3 - 8 } & & \multicolumn{2}{|c|}{ High } & \multicolumn{2}{|c|}{ Middle } & \multicolumn{2}{|c|}{ Low } \\
\cline { 2 - 8 } & & EG & CG & EG & CG & EG & CG \\
\cline { 2 - 8 } & $s$ & 11.1 & 17.6 & 18.1 & 7.3 & 18.8 & 17.5 \\
\hline \multirow{3}{*}{ Female } & $\overline{\boldsymbol{X}}$ & 75.5 & 57.8 & 70.6 & 57.3 & 80.6 & 54.5 \\
\cline { 2 - 8 } & $s$ & 13.3 & 21.3 & 22.2 & 6.7 & 15.6 & 23.1 \\
\hline \multirow{3}{*}{ Total } & $\overline{\boldsymbol{X}}$ & 78.6 & 56.2 & 65.6 & 57.9 & 79.4 & 55.8 \\
\cline { 2 - 8 } & $s$ & 12.9 & 19.8 & 17.0 & 8.7 & 23.7 & 19.7 \\
\hline
\end{tabular}

Note: EG (Experiment Group), CG (Control Group)

Table I indicates that the average score of the students who were taught using RME approach was higher than those who were taught using conventional approach. An interesting finding was the students from the school with low category achieved the highest average score compared to the others.

Based on the learning styles, the average score of the students in the experimental group was higher than those in the control group, except for the students from the school with middle category. (see Table II)

TABLE II. THE AVERAGE SCORE OF STUDENTS' MATHEMATICAL REPRESENTATION ABILITY ACCORDING TO THEIR LEARNING STYLES AND SCHOOL CATEGORIES

\begin{tabular}{|l|l|l|l|l|l|l|l|}
\hline \multirow{2}{*}{$\begin{array}{c}\text { Learning } \\
\text { Style }\end{array}$} & \multirow{2}{*}{ Value } & \multicolumn{6}{|c|}{ Schools' Categories } \\
\cline { 3 - 8 } & & \multicolumn{2}{|c|}{ High } & \multicolumn{2}{|c|}{ Middle } & \multicolumn{2}{|c|}{ Low } \\
\cline { 2 - 8 } & & EG & CG & EG & CG & EG & CG \\
\hline \multirow{3}{*}{ Auditory } & $\overline{\boldsymbol{X}}$ & 74.2 & 52.4 & 57.6 & 60.4 & 76.3 & 56.2 \\
\cline { 2 - 8 } & $s$ & 10.2 & 22,0 & 19.9 & 8.8 & 18.9 & 22.0 \\
\hline \multirow{3}{*}{ Visual } & $\overline{\boldsymbol{X}}$ & 78.2 & 58.3 & 67.5 & 61.1 & 82.1 & 54.8 \\
\cline { 2 - 8 } & $s$ & 14.2 & 18.9 & 20.9 & 10.8 & 16.6 & 13.5 \\
\hline \multirow{3}{*}{ Kinesthetic } & $\overline{\boldsymbol{X}}$ & 91.7 & 63.3 & 73.3 & 56.2 & 72.5 & 55.6 \\
\cline { 2 - 8 } & $s$ & 6.8 & 15.1 & 20.3 & 3.8 & 23.7 & 25.4 \\
\hline
\end{tabular}

Note: EG (Experiment Group), CG (Control Group)

After conducting a series of normality and homogeneity tests, it was concluded that Mann Whitney U test was used for fourteen hypothesis testing, while the t-test was used for four hypothesis testing. The summary of the hypothesis testing, with the help of SPSS program, is presented in the two following tables.

TABLE III. THE RESULTS OF HYPOTHESIS TESTING BASED ON TOTAL AND GENDER COMPARISONS

\begin{tabular}{|l|c|c|c|}
\hline \multirow{2}{*}{ Gender } & \multicolumn{3}{|c|}{ Schools' Categories } \\
\cline { 2 - 4 } & High & Middle & Low \\
\cline { 2 - 4 } & Sig. & Sig. & Sig. \\
\hline Male & 0.000 & 0.871 & 0.003 \\
\hline Female & 0.015 & 0.002 & 0.002 \\
\hline Total & 0.012 & 0.046 & 0.002 \\
\hline
\end{tabular}

The results of hypothesis testing in Table 4 show that there were nine null hypotheses according to the total and gender comparison that were rejected because all the significant values of the testing were less than $\alpha=0.05$.It means that the mathematical representation ability of the students who were taught using RME approach was significantly higher than those were taught using conventional approach. This finding was also valid for male and female students in each category of schools.

Similar results were found for comparison involving students' learning styles (see Table IV).

TABLE IV. THE RESULTS OF HYPOTHESIS TESTING BASED ON THE LEARNING STYLES COMPARISONS

\begin{tabular}{|l|l|l|l|}
\hline \multirow{2}{*}{ Learning Style } & \multicolumn{3}{|c|}{ Schools' Criteria } \\
\cline { 2 - 4 } & High & Middle & Low \\
\cline { 2 - 4 } & Sig. & Sig. & Sig. \\
\hline Auditory & 0,006 & 0,648 & 0,010 \\
\hline Visual & 0,023 & 0,064 & 0,021 \\
\hline Kinesthetic & 0,011 & 0,008 & 0,004 \\
\hline
\end{tabular}

The results of nine hypothesis testing presented on Table 4 revealed that the mathematical representation ability of the students who have auditory, visual, and kinesthetic learning styles that were taught using RME approach was respectively higher than those were taught using conventional approach, except for the students with auditory and visual learning styles at the school in the middle category. In the school of middle category, there was no significant different between mathematical representation ability of the students with auditory and visual learning styles who were taught using RME approach and those who were taught using conventional approach. The subsequent finding along with the 'surprising' result found in the school of middle category, need to be investigated further later on.

The results of the research above arose two important points. Firstly, the RME approach could be implemented in all level of schools in order to improve the students' mathematical representation ability. This finding has complemented the previous findings which concluded that RME approach is suitable for all level of education $[19,5,15]$. Secondly, the RME approach gives the same opportunity to male and female students to develop their mathematical representation ability so that they could perform better than the students in the conventional class. 


\section{CONCLUSIONS}

Based on the results of this research it can be concluded that the RME approach gives positive influence on students' mathematical representation ability in all school categories (high, middle, and low). This conclusion is also valid for male and female students as well as for each learning style, except for the students who has auditory learning style in the school of the middle category. In general, it can be concluded that the RME approach positively contributes to the improvement of students' mathematical representation ability.

\section{REFERENCES}

[1] D.L. Ball, et al, "Content knowledge for teaching: what makes it special?," Journal of Teacher Education, vol. 59 no. 5, pp. 389-4007, 2008

[2] M. Caligaris, G. Rodriguez, and L. Laugero, Learning styles and visualization in numerical analysis. In Procedia-Social and Behavioral Sciences 174(2015) 3696 - 3701, 2015.

[3] M. P. Chen, C. Y. Lee, and W. C. Shu, "Influence of Mathematical Representation and Mathematics Self-Efficacy on the Learning Effectiveness of Fifth Graders in Pattern Reasoning," International Journal of Learning, Teaching and Educational Research, vol. 13, no. 1, pp. 1-16, 2015.

[4] A. Fauzan, Applying Realistic Mathematics Education (RME) in Teaching Geometry in Indonesian Primary Schools. Enschede, The Netherlands: PrintPartners Ipskamp, 2002.

[5] A. Fauzan, et al, The Development of RME-based Geometry Course for Indonesian Primary Schools. In An Introduction to Educational Design Research. T. Plomp, T., N. Nieveen N. (Eds). The Netherlands: SLO, 2013

[6] A. Fauzan, and E. Yezita, Developing learning trajectory for teaching ration using RME approach. The Eight Konaspi Proceeding: Jakarta, 2016.

[7] F. Fennel, 2006. NCTM Bulletin, September 2006.

[8] H. Freudenthal, Revisiting mathematics education. Dordrecht, The Netherlands: Kluwer Academic, 1991

[9] K. Gravemeijer, Developing realistic mathematics education. Utrecht, The Nederlands: Freudenthal Institute, 1994

[10] K. Gravemeijer, Realistic mathematics education theory as guideline for problem-centered, interactive mathematics education in Sembiring, R., Hoogland, K., Dolk, M. (eds), A decade of PMRI in Indonesia. Utrecht: TenBrink, 2010.

[11] K.Gravemeijer, and P. Cobb, Design research from the Learning Design Perspective. Dalam Jan Ven Den Akker, et. al. An Introduction to Educational Design Research. London: Routledge, 2013.

[12] K. Gravemeijer, et al, "Shortcoming of Mathematics Education Reform in The Netherlands: A Paradigm Case?," Journal of Mathematics Thinking and Learning, vol. 18, no. 1, pp. 25 - 44, 2016.

[13] M. Hickendorff, "The effect of presenting multi digit mathematics problems in a realistic context on sixth graders' problem solving," Journal of Cognition and Instruction, vol. 31, no. 3, pp. 314 - 344, 2013.

[14] P. Irianti, Authentic Assessment. P4TK: Yogyakartade Lange, J. 1987. Mathematics, Insight, and Meaning. OW \& OC, Utrecht, The Netherlands, 2004.

[15] S. Larsen, and M. Zandieh, "Proofs and refutations in the undergraduate mathematics classroom," Journal of Educational Studies in Mathematics, vol. 67 no. 3, pp. 205-216, 2017.

[16] NCTM. Principles and Standards for school mathematics. NCTM: USA, 2000

[17] F. Ozyildirim, S. Ipek, and O. Akkus, "Seventh Grade Student's Translational Skills Among Mathematical Representations," The International Journal of Learning, vol. 16, no. 3, pp. 197-2004, 2009.
[18] C. L. Rasmussen, and K.D. King, "Locating starting points in differential equations: a realistic mathematics education approach," International Journal of Mathematical Education in Science and Technology, vol. 31 no. 2, pp. 161-172, 2000

[19] T. A. Romberg, and M. C. Shafer, The Impact of Reform Instruction on Student Mathematics Achievement: An Example of a Summative Evaluation of a Standards-Based Curriculum. New York: Routledge, 2008

[20] K. Sedig, "From Play to Thoughtful Learning: A Design Strategy to Engage Children With Mathematical Representations," Journal of Computers in Mathematics and Science Teaching, vol. 27, no. 1, pp. 65-101, 2008.

[21] A. C. Superfine, R. S. Canty, and A. M. Marshall, "Translation between external representation systems in mathematics: All-or-none or skill conglomerate?," The Journal of Mathematical Behavior, vol. 28 no. 4, pp. 217-236, 2009.

[22] A. Treffers, Three dimensions. A model of Goal and Theory Description in Mathematics Education, Dordrecht, The Netherlands: Reidel, 1987.

[23] D.C. Webb, et al., "Design Research in the Netherlands: Introducing Logarithms Using Realistic Mathematics Education," Journal of Mathematics Education at Teachers College. Spring-Summer 2011. Vol. 2, 2011. 